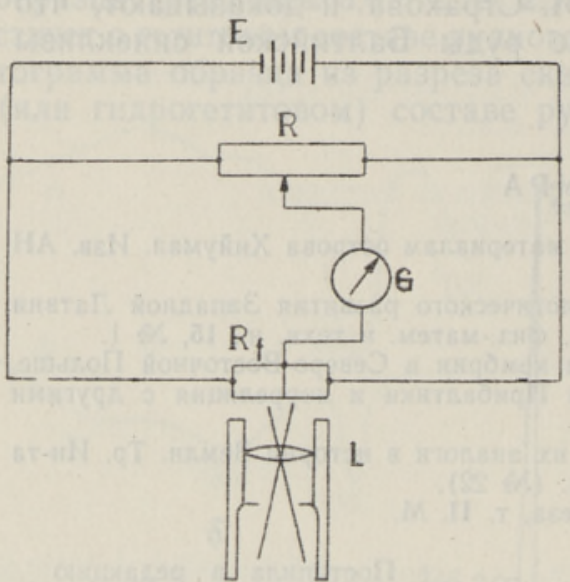

Рис. 1. Принципиальная схема электрооптической насадки для кварцевых гравиметров: $E-$ источник питания; $R$ - потенциометр; $R_{f}-$ фотосопротивление; $L$ - линза; $G$ - гальванометр или самопишущий прибор. пишущим микроамперметром. $\mathrm{Ha}$ рис. 2 приведена запись регистрации колебания маятника гравиметра ГАК-7Т № 668 при среднем микросейсмическом фоне по азимуту в разных направлениях.

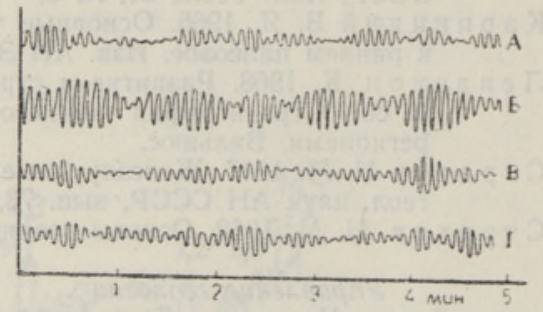

Рис. 2. Запись микросейсмического фона 1/I 1973 г. (14.00) по азимуту в разных направлениях маятника гравиметра: $A$ - северо-восточное; $B-$ юго-восточное; $B-$ южное; $\Gamma-$ восточное.

Насадка очень проста по конструкции и может применяться повсеместно для изучения влияния микросейсмических колебаний почвы на показания гравиметра.

Таллинский политехнический институт

Академии наук Эстонской ССР Ннститут геологии
Поступила в редакцию 4/IV 1973

EESTI NSV TEADUSTE AKADEEMIA TOIMETISED. 23. KOIDE KEEMIA * GEOLOOGIA. 1974, NR. 1

ИЗВЕСТИЯ АКАДЕМИИ НАУК ЭСТОНСКОП ССР. ТОМ 23 ХИМИЯ * ГЕОЛОГИЯ. 1974, № 1

\title{
НЕКОТОРЫЕ РЕЗУЛЬТАТЫ РАБОТ ЛАБОРАТОРИИ ВНИИМОРГЕО ПО УВЕЛИЧЕНИЮ НАДЕЖНОСТИ ИЗМЕРЕНИЙ АКТИВНОСТИ ПРИРОДНОГО РАДИОУГЛЕРОДА
}

V. VEKSLER, A. SAVVAITOV, V. STELLE. OLELIIDULISES MEREGEOLOOGIA JA -GEOFOOSIKA TEADUSLIKU UURIMISE INSTITUUDIS (RIIA) TAIUSTATUD LOODUSLIKU RADIOSUSINIKU AKTIIVSIJSE MOOTMISE METOODIKA

V. VEKSLER, A. SAVVAITOV, $V$. STELLE. SOME RESULTS OF THE WORK OF THE RADIOCARBON LABORATORY OF THE ALL-UNION RESEARCH INSTITUTE OF MARINE GEOLOGY AND GEOPHYSICS (RIGA), CONCERNING THE RELIABILITY OF MEASUREMENTS OF NATURAL RADIOCARBON ACTIVITY

В последние годы в радиоуглеродной лаборатории Всесоюзного научно-исследовательского института морской геологии и геофизики (ВНИИМОРГЕО) проводились некоторые методические исследования 
по повышению достоверности датирования образцов по радиоуглероду за счет точности радиометрических измерений.

Постановка этих исследований особенно важна для определения абсолютного возраста образцов из морских отложений, датирование которых связано с трудностями ввиду их малого объема и, соответственно, уменьшенного выхода из них бензола.

Радиометрические измерения активности природного радиоуглерода проводились на установках, параметры которых приведены в табл. 1.

Таблица 1

Параметры радиоуглеродных установок

\begin{tabular}{|c|c|c|c|c|c|c|}
\hline $\begin{array}{l}\text { Объем } \\
\text { сцинтил- } \\
\text { лятора, } \\
\text { м. }\end{array}$ & $\begin{array}{c}\text { Уста- } \\
\text { нов- } \\
\text { ка }\end{array}$ & $\begin{array}{l}\text { Фон } N_{\phi}, \\
\text { uмn/мuн }\end{array}$ & $\begin{array}{c}\text { Чистый } \\
\text { счет совре- } \\
\text { менного } \\
\text { углерода } N_{\text {a }} \text {, } \\
\text { имп/мин }\end{array}$ & $\begin{array}{c}\text { Показа- } \\
\text { тель каче- } \\
\text { ства } \\
N_{\partial} / \sqrt{N_{\Phi}}\end{array}$ & $\begin{array}{c}\text { Эффектив- } \\
\text { ность реги- } \\
\text { страции } \\
\mathrm{C}^{14}, \%\end{array}$ & $\begin{array}{l}\text { Предель- } \\
\text { ный воз- } \\
\text { раст, лет }\end{array}$ \\
\hline $\begin{array}{r}5 \\
10 \\
10 \\
3 \\
2 \\
5\end{array}$ & $\begin{array}{l}1 \\
1 \\
2 \\
3 \\
4 \\
4\end{array}$ & $\begin{array}{l}1,604 \\
2,710 \\
5,65 \\
1,80 \\
1,08 \\
1,22\end{array}$ & $\begin{array}{l}16,689 \\
32,780 \\
45,85 \\
13,00 \\
14,30 \\
35,45\end{array}$ & $\begin{array}{r}13,2 \\
19,9 \\
19,2 \\
9,7 \\
13,7 \\
32,1\end{array}$ & $\begin{array}{l}31,4 \\
29,7 \\
41,2 \\
39,3 \\
65,0 \\
64,0\end{array}$ & $\begin{array}{l}39000 \\
42100 \\
41900 \\
33200 \\
29200 \\
45600\end{array}$ \\
\hline
\end{tabular}

Пр и меч а и е: 1 - полупроводниковая одноканальная установка (Векслер, Путанс, Савваитов, 1971); 2 - одноканальная установка из стандартных блоков ПД-2-1, в которой для обеспечения более стабильной работы собственный усилитель БУ-2-1 заменен опектрометрическим усилителем УИС-2М; 3 - одноканальная установка (производство ГДР), состоящая из источника высокого напряжения, линейного усилителя VA-V-100, счетчика VA-G-120 и цифропечатающего устройства; 4 - многоканальная установка на интегральных микросхемах.

По результатам выполненных исследований наибольшая точность радиометрических измерений на одноканальной сцинтилляционной установке (Векслер, Путанс, Савваитов, 1971) достигается регистрацией активности $\beta$-излучения $\mathrm{C}^{14}$ на энергетическом участке максимального насыщения. Работа установки в режиме максимального насыщения, так наз работа в точке баланса (Arnold, 1954), обеспечивается выбором такого общего усиления, при котором амплитуда почти у $100 \%$ импульсов будет превышать уровень нижнего порога дискриминации. При этом условии интегральная скорость счета выходит на плато. Когда все импульсы будут достаточно велики, скорость счета в окне после прохождения максимума может падать. Для максимальной стабильности измерений уровни дискриминации и напряжения на ФЭУ необходимо устанавливать так, чтобы амплитуды лишь некоторых импульсов (малой их части от общего числа) превышали значение верхнего уровня.

Результаты достигнутой стабильности измерений приведены в табл. 2.

При этих оптимальных условиях незначительные ослабления амплитуды импульсов из-за оптического поглощения, тушения, дрейфа усилителя и прочих причин не изменяют значений скорости счета.

Достоверность измерения активности радиоуглерода проверялась счетом сцинтилляционных препаратов параллельно на двух установках.

Однако достигнутая точность измерений снижает в целом эффективность регистрации радиоуглерода, уменьшая показатель качества уста- 
Результаты измерения воспроизводимости скорости счета эталона современного С14 (при объеме сцинтиллятора 5 мл)

\begin{tabular}{|c|c|c|c|c|}
\hline Скорость & Статистиче- & $\begin{array}{l}\text { Среднее зна- } \\
\text { чение скорости }\end{array}$ & \multicolumn{2}{|c|}{ Отклонение от среднего } \\
\hline uмn/мuн & $\%$ & $\begin{array}{c}\text { счета эталона, } \\
\text { uмn/suн }\end{array}$ & uмn $/$ мuн & $\%$ \\
\hline 77,69 & 0,3 & 77,63 & $-0,06$ & 0,07 \\
\hline 77,48 & 0,3 & 77,63 & $+0,15$ & 0,19 \\
\hline 77,75 & 0,3 & 77,63 & $-0,12$ & 0,15 \\
\hline 77,61 & 0,3 & 77,63 & $+0,02$ & 0,30 \\
\hline 77,38 & 0,3 & 77,63 & $+0,25$ & 0,30 \\
\hline 77,86 & 0,3 & 77,63 & $-0,23$ & 0,30 \\
\hline
\end{tabular}

Примеч ание: приведенные данные характеризуют пятикратный эталон.

новки, что особенно отрицательно сказывается при измерениях на малых объемах сцинтиллятора.

По данным наших исследований, эффективность регистрации может быть улучшена за счет снижения фона как от космического излучения, так и от электромагнитных наводок. В связи с этим разработана установка на интегральных микросхемах. Монтаж установки позволяет всю схему тракта усиления, дискриминации и логики разместить непосредственно в защите детектора излучения, обеспечивая тем самым надежную экранировку от паразитных наводок и электромагнитного излучения. Применение временной селекции импульсов позволяет дискриминировать фон от космического излучения.

Кроме того, на общую эффективность измерения активности природного радиоуглерода влияет выбор оптимального времени счета сцинтилляционных препаратов образца, фона и эталона. В большинстве лабораторий принятая методика датирования заключается в измерениях по схеме: образец $\rightarrow$ фон $\rightarrow$ эталон $\rightarrow$ фон $\rightarrow$ и т. д. Процесс измерения каждого из компонентов схемы длится не менее 24 ч. Анализ статистических данных (Векслер, 1971) позволяет задавать общее время измерений исходя из средней ошибки для возрастного диапазона. Требуемая точ ность измерений при минимальной затрате времени достигается правильным соотношением времен счета эталона, фона и образца. Оптимальный выбор сокращает общее время измерения до $50 \%$ с сохране нием задаваемой точности.

Применение результатов выполненных исследований при серийных определениях позволяет повысить точность и общую эффективность датирования образцов по радиоуглероду.

\section{ЛИТЕРАТ У РА}

Векслер В. С., Путанс Б. Д., Савваитов А. С. 1971. Радиоуглерод (Мат-лы Всесоюз. совещ. по проблеме «Вариации содерж. радиоуглерода в атмосфере Земли и радиоуглеродное датирование». Вильнюс, $22-24$ ноября 1971 г.). Вильнюс.

В екслер В. 1974. Стандартизация процесса измерения активности $\mathrm{C}^{14}$ и обработки результатов. Изв. АН ЭССР. Хим. Геол., 23 (в печати).

A r nold J. R. 1954. Science, 119, No. 155. 